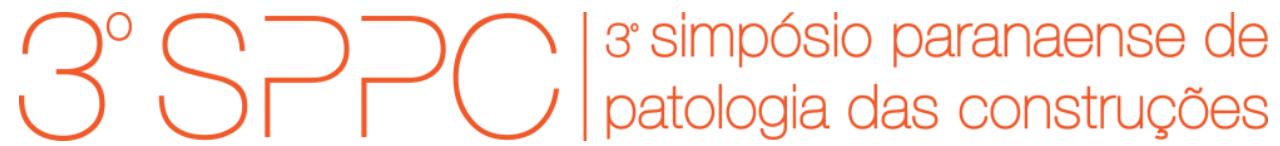

ISSN 2526-7248 artigo n. 3SPPC1004, pp. 35-46, 2018

\title{
Escolha de produtos para proteção de superfície em concretos frente à ação de íons cloretos em zonas marítimas: uma aplicação da Análise Hierárquica (AHP)
}

\author{
Oliveira, Isaac Aguiar ${ }^{1}$; Medeiros, Marcelo Henrique Farias de 2 \\ ${ }^{1}$ Especialista, Universidade Federal do Paraná, zacaguiar@gmail.com \\ 2 Doutor, Universidade Federal do Paraná, medeiros.ufpr@gmail.com
}

\begin{abstract}
Resumo: Os elementos estruturais de concreto armado sofrem deterioração em zonas marítimas principalmente por íons cloreto. Diversos tipos de protetores de superfície podem ser aplicados para redução da entrada destes agentes deletérios e para que possam aumentar o tempo de vida útil da estrutura. O objetivo deste estudo é discutir sobre a escolha de qual o melhor produto de proteção de superfície para garantir bom desempenho quanto à absorção de água, corrosão e penetração de cloretos. Foram utilizados onze tipos de protetores que se dividem em três classificações: Formadores de Películas, Hidrofugantes de Superfície e os Bloqueadores de Poros. Para a tomada de decisão foi utilizada a Análise Hierárquica (AHP), a qual compara o desempenho dos protetores de superfície aplicados. Para a análise dos dados foi montada uma árvore de hierarquia para reduzir a subjetividade das comparações par a par e dar maior confiabilidade nas escolhas. Os protetores que obtiveram melhores desempenhos em ordem decrescente foram os vernizes poliuretânicos que são formadores de películas, em segundo foram os hidrofugantes de superfície à base de solventes e por último os bloqueadores de poros à base de silicato de sódio líquido. A Análise Hierárquica se mostrou uma ferramenta eficaz neste processo de decisão.
\end{abstract}

Palavras-chave: Protetores de superfície, Formadores de películas, Hidrofugantes de superfície, Bloqueadores de poros, Penetração de cloretos.

Abstract: The structural elements of reinforced concrete suffer deterioration in marine zones mainly by chloride ions. Several types of surface protectors could be applied to reduce the entrance of harmful agents and increase the lifetime of the structure. Thus, the aim of this paper is to discuss which is the best surface protection product to ensure a satisfactory level of performance against the water absorption, corrosion and chlorides ion penetration. We used a decision tool, Analytic Hierarchy Process (AHP), which compares the performance of the surface protectors applied on the concrete. Eleven types of protectors were used, which are classified in three levels: film formers, hydrophobic surface and pore blockers. For data analysis, a Hierarchy Tree was created to decrease the subjectivity of the process of pairwise comparisons and improve the reliability of the choices. The protectors that had the best performances were the film formers solvent-base coatings, secondly the hydrophobic surface solvent-base and thirdly pore blockers liquid water glass. At the end, the Analytic Hierarchy Process proved to be a good tool for decision-making.

Keywords: Surface protection, Film formation, Hydrophobic surface, Pore blocking, Penetration of chloride. 
OLIVEIRA, I. A; MEDEIROS, M. H. F., ESCOLHA DE PRODUTOS PARA PROTEÇÃO DE SUPERFÍCIE EM CONCRETOS FRENTE À AÇÃO DE ÍONS CLORETOS EM ZONAS MARÍTIMAS: UMA APLICAÇÃO DA ANÁLISE HIERÁRQUICA (AHP). $3^{\circ}$ Simpósio

Paranaense de Patologia das Construções (30 SPPC), artigo 3SPPC1004, pp. 35 - 46, 2018. DOI: 10.4322/2526-7248.004

\section{Introdução}

As estruturas de concreto podem conter macrofissuras, microfissuras e vazios descontínuos. Através destes danos as estruturas podem sofrer infiltrações que contribuam para perdas de durabilidade, sejam por ataques físicos, ataques químicos ou por efeitos de molhagem/secagem. Assim, elementos de concreto sujeitos a estas ações podem apresentar perdas graduais da estanqueidade, principalmente pela interconexão destas fissuras [1,2]. Mesmo um concreto sendo cuidadosamente dosado, é necessário que se tenha consciência de sua durabilidade, para que não ocorra casos de sua estrutura sofrer deterioração prematura [3]. De acordo com a ACI Committee 201 (2008) [4], a durabilidade do concreto de cimento hidráulico pode ser definida como a habilidade de resistir às ações das intempéries, ataques químicos, abrasão e outros processo de deterioração.

Os elementos em concreto armado de zonas marítimas apresentam maior probabilidade de iniciar processos de deterioração mais precocemente, isto devido à eficaz penetração de agentes agressivos, como os de íons cloretos [5]. Assim, uma peça de concreto em ambiente caracterizado com alto teor de cloretos pode apresentar cinética de um processo de difusão no estado não estacionário [6].

Os meios de proteção de superfície em estruturas de concreto podem ser utilizados tanto para estruturas novas como para estruturas antigas, porém é aconselhável que estes produtos não sejam utilizados antes que a estrutura conclua o seu processo de hidratação, fato que pode reduzir a eficiência de estanqueidade do mesmo [7, 8]. A norma EN 1504 [9] estabelece que para o ingresso de água por capilaridade ou absorção superficial não deva exceder taxa de $0,1 \mathrm{~kg} / \mathrm{m}^{2} / \mathrm{h} 1 / 2$.

As proteções de superfície objetivam encapar o concreto com um filme não penetrável, formando uma barreira entre o ambiente e a superfície do concreto, trazendo considerável proteção para estes elementos contra agentes agressivos, reduzindo a sua umidade interna e preservando o seu ambiente alcalino $[8,10]$. Este sistema funciona, fundamentalmente, para a proteção da armadura no concreto [11].

Como o campo dos protetores de superfície é amplo, podem gerar dúvidas na escolha de qual o tipo ideal para cada situação, pois existem diversas marcas e diferentes características entre eles [12]. Assim, torna-se importante conhecer as classificações dos produtos de proteção. Na Figura 1 são apresentados os grupos de tratamento de superfície para concretos.

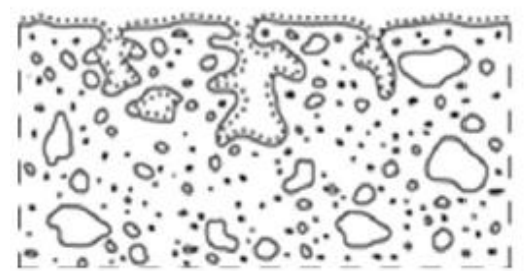

(A)

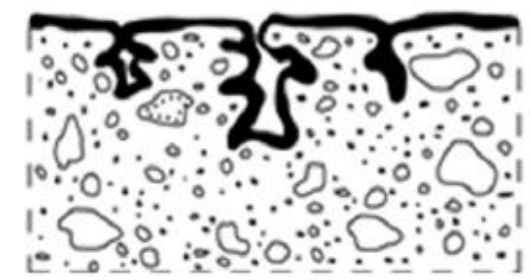

(B)



(C)

Figura 1: Representação esquemática dos diferentes tipos de Protetores de Superfície de Concreto: (A) Hidrofugantes de Superfície (B) Bloqueadores de Poros (C) Formadores de Películas. Fonte: Baltazar et al (2014) [13] 
OLIVEIRA, I. A; MEDEIROS, M. H. F., ESCOLHA DE PRODUTOS PARA PROTEÇÃO DE SUPERFÍCIE EM CONCRETOS FRENTE À AÇÃO DE ÍONS CLORETOS EM ZONAS MARÍTIMAS: UMA APLICAÇÃO DA ANÁLISE HIERÁRQUICA (AHP). $3^{\circ}$ Simpósio

Paranaense de Patologia das Construções (30 SPPC), artigo 3SPPC1004, pp. 35 - 46, 2018. DOI: 10.4322/2526-7248.004

\subsection{Revestimento formadores de películas}

Os produtos poliméricos formadores de película têm a propriedade de formar um filme sólido e podem ser divididos em vernizes e tintas. Os vernizes são constituídos de solventes, resinas e aditivos, já as tintas são constituídas por solventes, resinas, aditivos e pigmentos [14]. Sobre os constituintes vale ressaltar que, os solventes são veículos, geralmente voláteis, que dissolvem as resinas e conferem adequada viscosidade à mistura, as resinas são veículos poliméricos não voláteis, os pigmentos são substâncias responsáveis pela cor, brilho, opacidade, atividade química protetiva e carga inerte e os aditivos conferem características às tintas, podendo ter função de rápida secagem, antimofo e plastificante por exemplo [11], [14].

\subsection{Revestimento bloqueadores de poros}

Este revestimento, geralmente à base de silicatos de sódio ou silicato à base flúor, podem provocar ganhos em termos de dureza superficial, durabilidade química, resistência à abrasão e redução da permeabilidade [6], [11], [15]. Thompson et al. (1997) [15] apresenta possível reação de colmatação que ocorre nos poros superficiais, então, após a aplicação do silicato de sódio ele reagirá com o hidróxido de cálcio que formarão como produtos o gel de C-S-H (CaO-SiO2.H2O) e o hidróxido de sódio, como pode ser visto na Eq. 1:

$$
\mathrm{Na}_{2} \mathrm{SiO}_{3}+\mathrm{H}_{2} \mathrm{O}+\mathrm{Ca}(\mathrm{OH})_{2} \rightarrow \mathrm{CaO} \cdot \mathrm{SiO}_{2} \cdot \mathrm{H}_{2} \mathrm{O}+2 \mathrm{NaOH}
$$

Esta reação dificilmente ocorrerá em estruturas carbonatadas, pois a portlandita em vez de reagir com o silicato de sódio aplicado, reagirá com o dióxido de carbono do ar dando origem ao carbonato de cálcio, assim, em concretos com superfície carbonatada é necessário realizar impregnação com hidróxido, ou seja, realcalinizar a superfície do elemento antes da aplicação do silicato de sódio para o resultado ser efetivo [11]. No entanto, Bertolini et al (2013) [6] sugere a Eq. 2, ele mostra que a reação com o dióxido de carbono é presente na reação principal, mesmo a estrutura não estando carbonatada terá um dos produtos carbonatos alcalinos o qual poderá causar eflorescência na peça.

$$
\mathrm{Na}_{2} \mathrm{SiO}_{4}+\mathrm{Ca}(\mathrm{OH})_{2}+\mathrm{CO}_{2} \rightarrow \mathrm{CaO} \cdot \mathrm{SiO}_{2} \cdot \mathrm{H}_{2} \mathrm{O}+2 \mathrm{Na}_{2} \mathrm{CO}_{3}+\mathrm{H}_{2} \mathrm{O}
$$

Neste processo haverá redução da absorção de água, porém não será efetiva, pois o gel de C-S-H formado é hidrofílico, fator que diminui a efetividade de proteção das peças de concreto.

\subsection{Revestimento hidrofugantes de superfície}

Estes produtos com base de impregnação hidrófoba originam-se das resinas de silicone, este tipo de produto reveste internamente os poros, formando uma barreira contra a entrada de umidade [16]. Pelo contrário, o filme hidrófobo permite a livre circulação do vapor de água, que afasta o risco de condensação e aprisionamento da umidade dentro da peça de concreto [11]. Dentre os grupos dos silicones, os produtos mais utilizados para a hidrofobização do concreto são os compostos por silanos e siloxano, as suas estruturas moleculares são apresentadas na Figura 2. 
OLIVEIRA, I. A; MEDEIROS, M. H. F., ESCOLHA DE PRODUTOS PARA PROTEÇÃO DE SUPERFÍCIE EM CONCRETOS FRENTE À AÇÃO DE ÍONS CLORETOS EM ZONAS MARÍTIMAS: UMA APLICAÇÃO DA ANÁLISE HIERÁRQUICA (AHP). $3^{\circ}$ Simpósio Paranaense de Patologia das Construções (30 SPPC), artigo 3SPPC1004, pp. 35 - 46, 2018. DOI: 10.4322/2526-7248.004<smiles>CO[Si](C)(C)O</smiles>

(A) Silano<smiles>CO[Si](C)(C)O[Si](C)(C)O[Si](C)(C)O[Na]</smiles>

(B) Siloxano $(n=1,2, \ldots, 5)$

Figura 2: Moléculas de (A) Silano e (B) Siloxano. Fonte: Bertolini et al (2013) [6]

\section{Objetivo}

O objetivo deste trabalho é aplicar a AHP (Analytic Hierarchy Process), Análise Hierárquica, para o processo de escolha do revestimento de proteção de superfície frente à ação de íons cloreto. Para esta análise foram listados três grupos de proteção, variando suas composições conforme apresenta a Tabela 1. Para avaliação destes três tipos de revestimentos foram realizados os experimentos listados na Tabela 2 com o objetivo de mensurar quais dos produtos obtiveram 0 melhor desempenho em termos de eficiência na superfície da peça de concreto.

Tabela 1: Descrição dos Produtos de Proteção de Superfície

\begin{tabular}{|c|c|c|c|}
\hline Grupo & $\begin{array}{l}\text { Sistema de } \\
\text { Proteção }\end{array}$ & Identificação & Descrição do fabricante \\
\hline \multirow[t]{3}{*}{$\begin{array}{l}\text { Hidrofugante } \\
\text { de Superfície }\end{array}$} & \multirow[t]{3}{*}{ Simples } & Hidrofugante A & Hidrofugante silano/siloxano - base água \\
\hline & & Hidrofugante B & Hidrofugante silano/siloxano - base solvente \\
\hline & & Hidrofugante $\mathrm{C}$ & Hidrofugante silano/siloxano - base solvente \\
\hline \multirow{5}{*}{$\begin{array}{l}\text { Formadores } \\
\text { de Película }\end{array}$} & \multirow[t]{5}{*}{ Simples } & Acrílico 1 & Vernizacrílico - base solvente \\
\hline & & Acrílico 2 & Vernizacrílico - base solvente \\
\hline & & Acrílico 3 & Vernizacrílico - base água \\
\hline & & PU 1 & Verniz poliuretano alifático (bicomponente) \\
\hline & & PU 2 & Verniz poliuretano alifático (bicomponente) \\
\hline \multirow[t]{3}{*}{$\begin{array}{l}\text { Bloqueadores } \\
\text { de Poros }\end{array}$} & \multirow[t]{3}{*}{ Simples } & $\begin{array}{l}\text { Silicato de sódio } \\
(20 \%)\end{array}$ & $\begin{array}{l}\text { Solução aquosa de silicato de sódio com } 20 \% \text { de } \\
\text { concentração }\end{array}$ \\
\hline & & $\begin{array}{c}\text { Tratamento } \\
\text { Comercial } \\
\text { a base de silicato }\end{array}$ & $\begin{array}{l}\text { Produto a base de silicato de sódio comercializado para } \\
\text { proteção e impermeabilização do concreto }\end{array}$ \\
\hline & & $\begin{array}{l}\text { Silicato de sódio } \\
\text { líquido }\end{array}$ & Silicato de sódio líquido \\
\hline
\end{tabular}

Fonte: adaptado de Medeiros (2008) [11]

Tabela 2: Critérios de avaliação (experimentos)

\begin{tabular}{c}
\hline Critérios \\
\hline Potencial de Corrosão (E corr - mV) \\
\hline Velocidade de Corrosão (i corr) \\
\hline Carga Passante $(\mathrm{C})$ \\
\hline Coeficiente de difusão de cloretos $\left(\mathrm{cm}^{2} / \mathrm{s}\right)$ \\
\hline Profundidade de penetração de $\mathrm{Cl}(\mathrm{mm})$ \\
\hline Absorção de água por imersão $\left(\mathrm{kg} / \mathrm{m}^{2}\right)$ \\
\hline Absorção de água por capilaridade $\left(\mathrm{kg} / \mathrm{m}^{2}\right)$ \\
\hline Absorção de água pelo ensaio de pipeta $\left(\mathrm{kg} / \mathrm{m}^{2}\right)$
\end{tabular}


OLIVEIRA, I. A; MEDEIROS, M. H. F., ESCOLHA DE PRODUTOS PARA PROTEÇÃO DE SUPERFÍCIE EM CONCRETOS FRENTE À AÇÃO DE ÍONS CLORETOS EM ZONAS MARÍTIMAS: UMA APLICAÇÃO DA ANÁLISE HIERÁRQUICA (AHP). $3^{\circ}$ Simpósio

Paranaense de Patologia das Construções (30 SPPC), artigo 3SPPC1004, pp. 35 - 46, 2018. DOI: 10.4322/2526-7248.004

\section{Modelo Experimental}

Durante o programa experimental o concreto do substrato foi fixado com a consistência de $10 \pm 1 \mathrm{~cm}$ medida pelo "slump test". Para a definição do traço do concreto foi adotado o procedimento de dosagem de Helene e Terzian (1992). O cimento utilizado foi o CPII-E32 e a Tabela 3 apresenta os proporcionamentos dos materiais determinados por Medeiros (2008) [11]. Este traço foi adotado como padrão porque ele corresponde a um fck entre 25 e $30 \mathrm{MPa}$, resistência que é a realidade da maioria das obras brasileiras.

Tabela 3: Concreto adotado como padrão para desenvolvimento do trabalho

\begin{tabular}{c|c|c|c|c|c|c|c}
\hline $\begin{array}{c}\text { Proporção } \\
\text { (Cimento:Agregados) }\end{array}$ & $\begin{array}{c}\text { Teor de } \\
\text { argamassa } \\
(\%)\end{array}$ & $\begin{array}{c}\text { Cimento } \\
(\mathrm{kg})\end{array}$ & $\begin{array}{c}\text { Areia } \\
(\mathrm{kg})\end{array}$ & $\begin{array}{c}\text { Brita } \\
(\mathrm{kg})\end{array}$ & $\begin{array}{c}\text { Relação } \\
\mathrm{a} / \mathrm{c}\end{array}$ & $\begin{array}{c}\text { Consumo de } \\
\text { cimento } \\
\left(\mathrm{kg} / \mathrm{m}^{3}\right)\end{array}$ & $\begin{array}{c}\mathrm{H} \\
(\%)\end{array}$ \\
\hline Traço 1:4,5 & 51 & 1 & 1,8 & 2,7 & 0,525 & 358 & 9,5 \\
\hline
\end{tabular}

Fonte: Medeiros (2008) [11]

\subsection{Metodologia AHP (Análise Hierárquica)}

A aplicação da técnica AHP apresenta a necessidade de um conjunto de alternativas. A Figura 3 apresenta a Árvore Hierárquica com três níveis, que serão foram avaliados para tomada de decisão sobre qual o tipo de revestimento de superfície obterá o melhor desempenho para uma estrutura em zona marítima frente à ação de íons cloretos.

Para efeito de comparação dos elementos presentes em cada camada hierárquica, foi utilizada uma escala de julgamentos da norma ASTM E 1765 (2002) [17], Tabela 4, para se ponderar o grau de importância dos níveis de análise, atribuindo pesos aos elementos que mais contribuem para o aumento da durabilidade do elemento de concreto.

Tabela 4: Escala de importância ASTM

\begin{tabular}{l|l}
\hline \multicolumn{2}{c}{ Escala de Importância } \\
\hline Igualdade de Atributos & 1 \\
\hline Importância Moderada & 3 \\
\hline Importância Forte & 5 \\
\hline Importância Muito Forte & 7 \\
\hline Extremamente Importante & 9 \\
\hline
\end{tabular}

Fonte: ASTM E 1765 (2002) [17]

No Nível 1 da Árvore Hierárquica é apresentada a divisão dos experimentos em três importâncias: Corrosão, Penetração de Cloretos e Penetração de Água. Para os ensaios de Corrosão foram agrupados os ensaios de Potencial de Corrosão, Velocidade de Corrosão e o de Carga Passante, para os de Penetração de Cloretos foram agrupados os ensaios de Difusão de Íons Cloretos e os de Profundidade de Íons Cloretos, já para os de Penetração de Água foram agrupados os ensaios de Penetração de Água pelo Ensaio de Absorção, Penetração de Água pelo Ensaio de Capilaridade e Penetração de Água pelo Ensaio da Pipeta. 
OLIVEIRA, I. A; MEDEIROS, M. H. F. ESCOLHA DE PRODUTOS PARA PROTEČ̃̃ DE SUPERFÍCIE EM CONCRETOS FRENTE À ACÃO DE ÍONS CLORETOS EM ZONAS MARÍTIMAS: UMA APLICAÇÃO DA ANÁLISE HIERÁRQUICA (AHP). $3^{\circ}$ Simpósio Paranaense de Patologia das Construções (30 SPPC), artigo ???, pp. ?? - ??, 2017. DOI: ?????????????
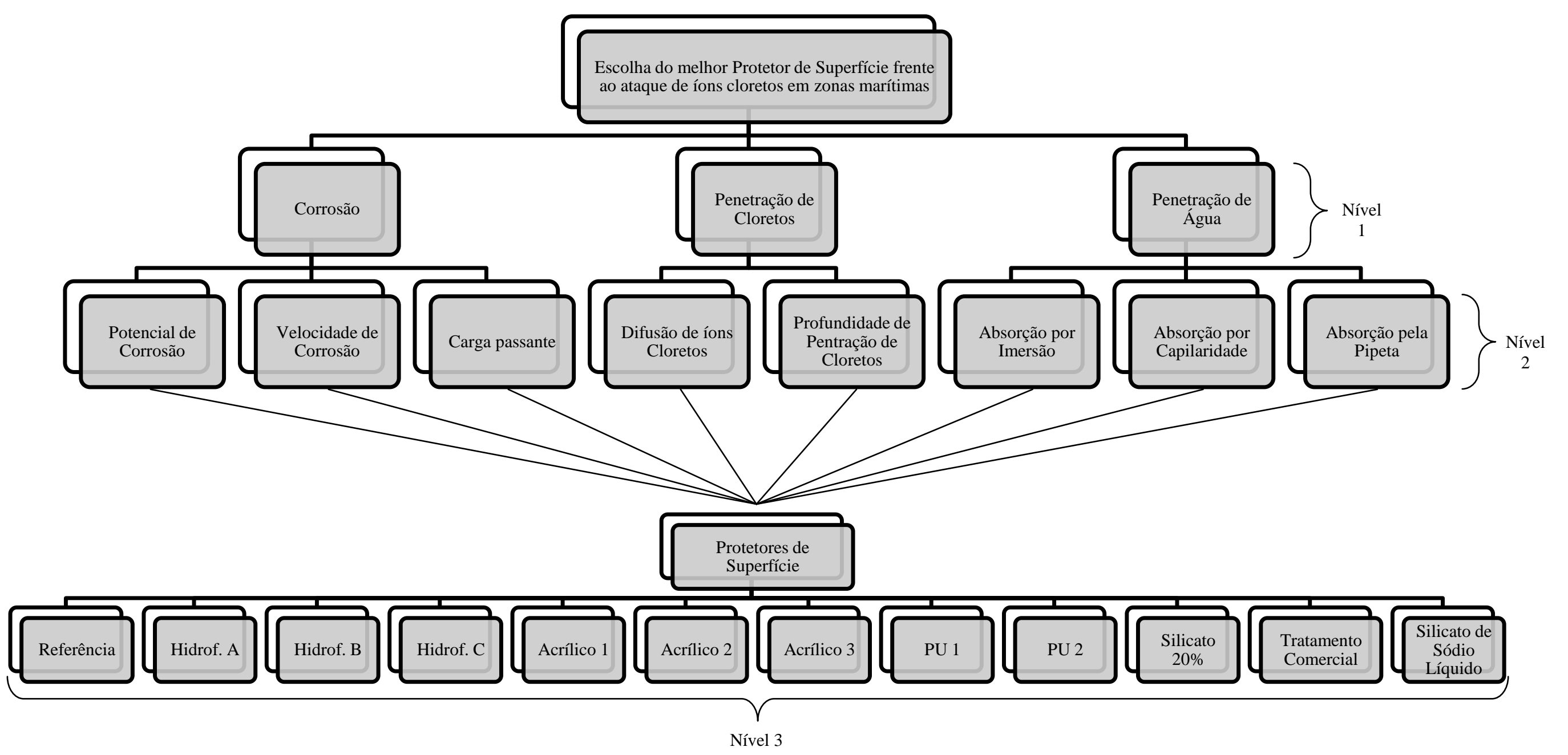

Figura 3: Organograma - Árvore de Hierárquia 
$\mathrm{Na}$ Tabela 5 são apresentados os valores da matriz de decisão do primeiro nível indicando os pesos de cada parâmetro. O ensaio de Penetração de Água foi considerado com Importância Moderada em relação aos demais por ser considerado que o principal meio de penetração dos cloretos no concreto seja por meio de águas que possam estar contaminadas com estes íons. Não descartando outras possibilidades, também pode ocorrer de o elemento estrutural já estar contaminado com cloretos, porém este tipo de contaminação foi considerado menos frequente que 0 anterior.

Tabela 5: Matriz de decisão - Nível 1 (Divisão dos experimentos)

\begin{tabular}{|c|c|c|c|c|c|}
\hline NÍVEL 1 & 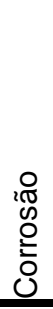 & 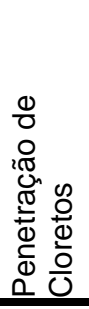 &  & 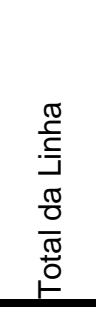 &  \\
\hline Corrosão & 1 & $1 / 3$ & $1 / 3$ & 1,67 & 0,13 \\
\hline Penetração de Cloretos & 3 & 1 & $1 / 3$ & 4,33 & 0,33 \\
\hline Penetração de Água & 3 & 3 & 1 & 7,00 & 0,54 \\
\hline TOTAL & & & & 13,00 & $100 \%$ \\
\hline
\end{tabular}

O segundo nível da Árvore Hierárquica é apresentado na Tabela 6, ela apresenta os ensaios propriamente ditos. Para o grupo dos ensaios de Corrosão foi atribuído mesmo grau de importância para todos os experimentos, isto porque ficou muito subjetivo e difícil selecionar qual dos três possuem maior relevância nesta aplicação. Para o segundo grupo, o ensaio de Profundidade de Penetração de Cloretos foi atribuído nota cinco, pois representa forte importância em relação aos demais, tal importância foi dada a este item porque a profundidade de cloretos quando avançada reduz o pH da região da armadura e acelera o processo de corrosão das armaduras. Para o terceiro grupo de ensaios, foi concedida maior nota ao Ensaio de Penetração de Água por Capilaridade, pois os autores consideraram ser mais comum a entrada de agentes deletérios por absorção de água nas peças estruturais, ou seja, a água servindo de veículo para estrada dos mesmos.

No Nível 3, apresentado pela Tabela 7, são apresentados os protetores de superfície. Todas as notas foram atribuídas levando em consideração o tipo de solvente dos produtos, as formulações químicas, funcionamento do protetor de superfície e o desempenho de cada produto como descrito na literatura.

Após atribuição das notas é necessário que se faça o somatório de cada linha gerando uma coluna auxiliar, a partir desta coluna efetua-se o somatório da mesma gerando um dado que será o somatório total das notas. Então, a partir desta coluna auxiliar e do somatório total consegue-se obter a porcentagem relativa de cada linha, esta porcentagem é o peso que será multiplicado pela tabela de resultados normalizados que será apresentada na seção dos resultados. 
OLIVEIRA, I. A; MEDEIROS, M. H. F., ESCOLHA DE PRODUTOS PARA PROTEÇÃO DE SUPERFÍCIE EM CONCRETOS FRENTE À AÇÃO DE ÍONS CLORETOS EM ZONAS MARÍTIMAS: UMA APLICAÇÃO DA ANÁLISE HIERÁRQUICA (AHP). $3^{\circ}$ Simpósio Paranaense de Patologia das Construções (30 SPPC), artigo 3SPPC1004, pp. 35 - 46, 2018. DOI: 10.4322/2526-7248.004

Tabela 6: Matriz de Decisão - Nível 2 (Experimentos)

\begin{tabular}{|c|c|c|c|c|c|c|c|c|c|c|c|}
\hline NÍVEL 2 &  & 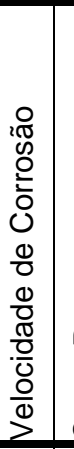 & 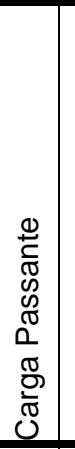 & 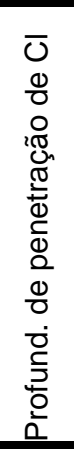 & 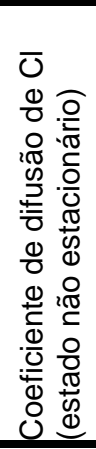 & 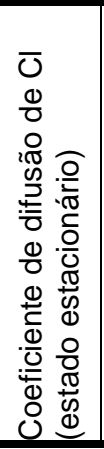 & 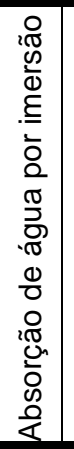 & 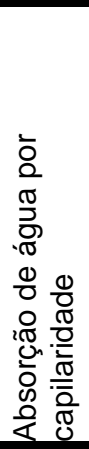 & 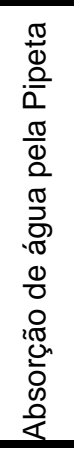 & 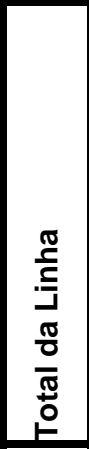 & 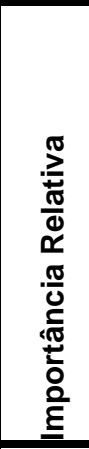 \\
\hline Potencial de Corrosão & 1 & 1 & 1 & & & & & & & 3,0 & 0,333 \\
\hline Velocidade de Corrosão & 1 & 1 & 1 & & & & & & & 3,0 & 0,333 \\
\hline Carga Passante & 1 & 1 & 1 & & & & & & & 3,0 & 0,333 \\
\hline Corrosão: TOTAL & & & & & & & & & & 9,0 & $100 \%$ \\
\hline Profundidade de penetração de cloretos & & & & 1 & 5 & 5 & & & & 11,0 & 0,714 \\
\hline $\begin{array}{r}\text { Coeficiente de difusão de cloretos } \\
\text { (estado não estacionário) }\end{array}$ & & & & $1 / 5$ & 1 & 1 & & & & 2,2 & 0,143 \\
\hline $\begin{array}{r}\text { Coeficiente de difusão de cloretos } \\
\text { (estado estacionário) }\end{array}$ & & & & $1 / 5$ & 1 & 1 & & & & 2,2 & 0,143 \\
\hline Penetração de Cloretos: TOTAL & & & & & & & & & & 15,4 & $100 \%$ \\
\hline Absorção de água por imersão & & & & & & & 1 & $1 / 3$ & 1 & 2,3 & 0,200 \\
\hline Absorção de água por capilaridade & & & & & & & 3 & 1 & 3 & 7,0 & 0,600 \\
\hline Absorção de água pelo ensaio de pipeta & & & & & & & 1 & $1 / 3$ & 1 & 2,3 & 0,200 \\
\hline Penetração de Água: TOTAL & & & & & & & & & & 11,7 & $100 \%$ \\
\hline
\end{tabular}

Tabela 7: Matriz de Decisão - Nível 3 (Protetores de Superfície)

\begin{tabular}{|c|c|c|c|c|c|c|c|c|c|c|c|c|c|c|}
\hline NÍVEL 3 & 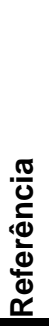 & 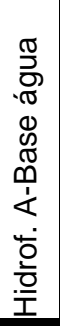 & 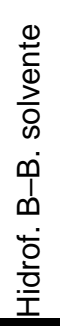 & 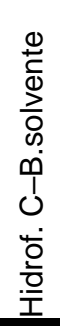 &  &  & 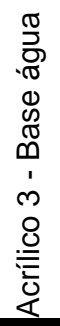 &  & 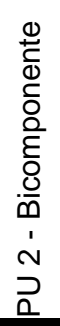 & 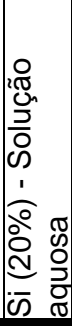 & 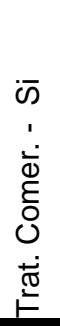 & 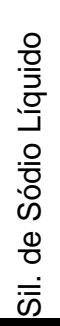 &  & 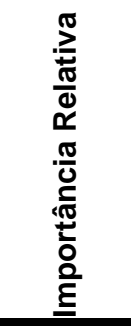 \\
\hline Referência & 1 & $1 / 3$ & $1 / 3$ & $1 / 3$ & $1 / 3$ & $1 / 3$ & $1 / 3$ & $1 / 5$ & $1 / 5$ & $1 / 2$ & $1 / 3$ & $1 / 3$ & 4,6 & 0,021 \\
\hline Hidrofugante $A$ - Base água & 3 & 1 & $1 / 3$ & $1 / 3$ & $1 / 3$ & $1 / 3$ & 1 & $1 / 3$ & $1 / 3$ & 1 & 1 & 1 & 10,0 & 0,047 \\
\hline Hidrofugante B - Base solvente & 3 & 3 & 1 & 1 & 1 & 1 & 1 & 1 & 1 & 3 & 3 & 3 & 22,0 & 0,103 \\
\hline Hidrofugante C - Base solvente & 3 & 3 & 1 & 1 & 1 & 1 & 1 & 1 & 1 & 3 & 3 & 3 & 22,0 & 0,103 \\
\hline Acrílico 1 - Base solvente & 3 & 3 & 1 & 1 & 1 & 1 & 3 & $1 / 3$ & $1 / 3$ & 3 & 3 & 3 & 22,7 & 0,106 \\
\hline Acrílico 2 - Base solvente & 3 & 3 & 1 & 1 & 1 & 1 & 3 & $1 / 3$ & $1 / 3$ & 3 & 3 & 3 & 22,7 & 0,106 \\
\hline Acrílico 3 - Base água & 3 & 1 & 1 & 1 & $1 / 3$ & $1 / 3$ & 1 & $1 / 5$ & $1 / 5$ & 1 & $1 / 3$ & $1 / 3$ & 9,7 & 0,046 \\
\hline PU 1 - Bicomponente & 5 & 3 & 1 & 1 & 3 & 3 & 5 & 1 & 1 & 3 & 3 & 3 & 32,0 & 0,150 \\
\hline PU 2 - Bicomponente & 5 & 3 & 1 & 1 & 3 & 3 & 5 & 1 & 1 & 3 & 3 & 3 & 32,0 & 0,150 \\
\hline Si (20\%) - Solução aquosa & 2 & 1 & $1 / 3$ & $1 / 3$ & $1 / 3$ & $1 / 3$ & 1 & $1 / 3$ & $1 / 3$ & 1 & $1 / 3$ & $1 / 3$ & 7,7 & 0,036 \\
\hline Tratamento Comercial - Base de Si & 3 & 1 & $1 / 3$ & $1 / 3$ & $1 / 3$ & $1 / 3$ & 3 & $1 / 3$ & $1 / 3$ & 3 & 1 & 1 & 14,0 & 0,066 \\
\hline Silicato de Sódio Líquido & 3 & 1 & $1 / 3$ & $1 / 3$ & $1 / 3$ & $1 / 3$ & 3 & $1 / 3$ & $1 / 3$ & 3 & 1 & 1 & 14,0 & 0,066 \\
\hline TOTAL & & & & & & & & & & & & & 213,3 & $100,00 \%$ \\
\hline
\end{tabular}


OLIVEIRA, I. A; MEDEIROS, M. H. F., ESCOLHA DE PRODUTOS PARA PROTEÇÃO DE SUPERFÍCIE EM CONCRETOS FRENTE À AÇÃO DE ÍONS CLORETOS EM ZONAS MARÍTIMAS: UMA APLICAÇÃO DA ANÁLISE HIERÁRQUICA (AHP). $3^{\circ}$ Simpósio

Paranaense de Patologia das Construções (30 SPPC), artigo 3SPPC1004, pp. 35 - 46, 2018. DOI: 10.4322/2526-7248.004

\section{Resultados e Discussão}

$\mathrm{Na}$ Tabela 8 são apresentados os resultados dos ensaios dos Protetores de Superfície e Referência. O elemento de Referência é a peça onde não foi aplicado nenhum tipo de sistema de proteção.

Tabela 8: Resultados dos experimentos realizados

\begin{tabular}{|c|c|c|c|c|c|c|c|c|c|c|c|c|}
\hline RESULTADOS & 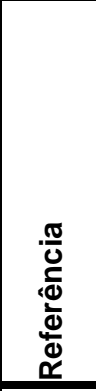 & 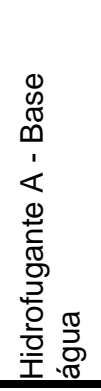 & 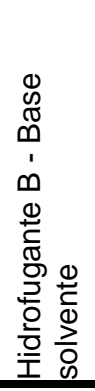 &  &  &  & 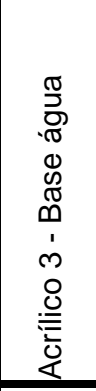 & $\begin{array}{l}\stackrel{0}{\leftrightarrows} \\
\frac{1}{0} \\
\frac{1}{0} \\
\frac{0}{E} \\
\frac{0}{0} \\
.0 \\
0 \\
1 \\
\frac{0}{2} \\
0\end{array}$ &  & 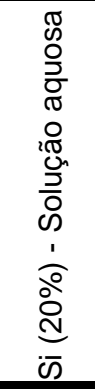 & 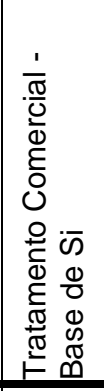 & 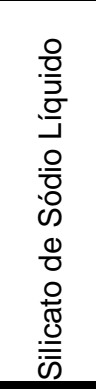 \\
\hline Potencial de Corrosão & -410 & -255 & -195 & -125 & -200 & -245 & -230 & -115 & -140 & -240 & -245 & -190 \\
\hline Velocidade de Corrosão & 0,18 & 0,03 & 0,03 & 0,02 & 0,03 & 0,03 & 0,03 & 0,02 & 0,02 & 0,03 & 0,03 & 0,01 \\
\hline Carga Passante & 1745 & 1496 & 1221 & 828 & 1062 & 515 & 1322 & 370 & 432 & 1403 & 893 & 1140 \\
\hline $\begin{array}{r}\text { Profund. de penetração } \\
\text { de } \mathrm{Cl}\end{array}$ & 42 & 32 & 29 & 18 & 25 & 17 & 23 & 3 & 6 & 30 & 15 & 21 \\
\hline $\begin{array}{r}\text { Coeficiente de difusão } \\
\text { de cloretos } \\
\text { (estado não } \\
\text { estacionário) } \\
\end{array}$ & 3,520 & 3,060 & 2,770 & 2,340 & 2,750 & 1,670 & 3,100 & 0,842 & 1,020 & 3,000 & 1,990 & 2,210 \\
\hline $\begin{array}{r}\text { Coeficiente de difusão } \\
\text { de cloretos } \\
\text { (estado estacionário) } \\
\end{array}$ & 8,08 & 2,661 & 1,257 & 0,656 & 1,341 & 0,913 & 2,212 & 0,371 & 0,466 & 2,881 & 0,908 & 1,375 \\
\hline $\begin{array}{r}\text { Absorção de água por } \\
\text { imersão }\end{array}$ & 14,8 & 7,7 & 5,2 & 2,4 & 10,1 & 8,0 & 14,1 & 2,7 & 4,1 & 13,3 & 13,5 & 12,9 \\
\hline $\begin{array}{r}\text { Absorção de água por } \\
\text { capilaridade }\end{array}$ & 6,6 & 2,2 & 1,3 & 0,3 & 1,1 & 0,3 & 2,1 & 0,2 & 0,2 & 2,0 & 1,9 & 2,0 \\
\hline $\begin{array}{r}\text { Absorção pelo ensaio } \\
\text { de pipeta }\end{array}$ & 8,1 & 4,5 & 2,5 & 1,2 & 2,9 & 1,1 & 2,6 & 1,1 & 1,2 & 8,1 & 7,3 & 7,6 \\
\hline
\end{tabular}

Para dar prosseguimento a análise de decisão, o método exige uma normalização dos dados da Tabela 8, para que seja possível a comparação entre os termos par a par.

Importante notar que, para todos os onze ensaios realizados quanto menor a grandeza do dado, melhor o desempenho do sistema de proteção, ou seja, todos os dados apresentam comportamento inversamente proporcional. Para executar 0 tratamento de normalização é necessário que todos os dados inversamente proporcionais sejam invertidos. Após inversão é necessário identificar o maior número de cada linha do critério e assim dividir toda a linha por este valor, através deste processo de cálculo todos os dados da linha se apresentarão com grandeza entre 0 e 1 , todas as linhas devem passar por este processo de cálculo, assim a matriz de decisão consegue acusar o material de maior nota como o de melhor desempenho.

Após a normalização dos dados é necessário executar a multiplicação dos pesos atribuídos das Tabela 5, Tabela 6 e Tabela 7 para se chegar nos resultados da Tabela 9. Então, para se obter o índice de desempenho de cada protetor é necessário efetuar o somatório da coluna e assim comparar os resultados. Para 
OLIVEIRA, I. A; MEDEIROS, M. H. F., ESCOLHA DE PRODUTOS PARA PROTEÇÃO DE SUPERFÍCIE EM CONCRETOS FRENTE À AÇÃO DE ÍONS CLORETOS EM ZONAS MARÍTIMAS: UMA APLICAÇÃO DA ANÁLISE HIERÁRQUICA (AHP). $3^{\circ}$ Simpósio

Paranaense de Patologia das Construções (30 SPPC), artigo 3SPPC1004, pp. 35 - 46, 2018. DOI: 10.4322/2526-7248.004

melhor visualização dos dados da Tabela 9 todos os dados foram multiplicados por 100.

Os dados que apresentaram melhor desempenho para os Hidrofugantes de Superfície foi o produto Hidrofugante $\mathrm{C}$ à base de solvente, para os Formadores de Película foi o Verniz Poliuretânico (PU 1 - bicomponente) e para os Bloqueadores de Poros foi o Silicato de Sódio Líquido.

Tabela 9: Desempenho - Protetor de Superfície

\begin{tabular}{|c|c|c|c|c|c|c|c|c|c|c|c|c|}
\hline $\begin{array}{c}\text { MULTIPLICAÇÃO: } \\
\text { RESULTADOS NORMALIZADOS } \\
\mathbf{X} \\
\text { NOTAS ATRIBUÍDAS }\end{array}$ & 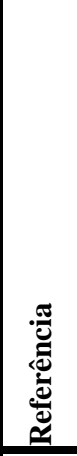 &  & 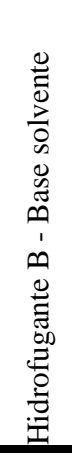 & 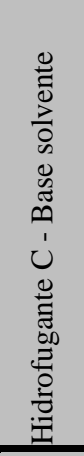 & 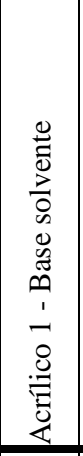 &  & 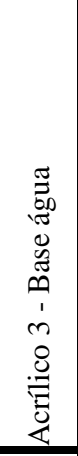 &  & 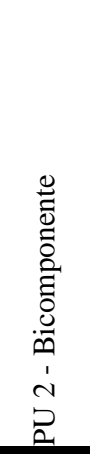 & 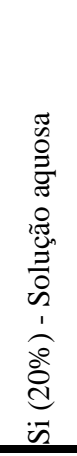 & 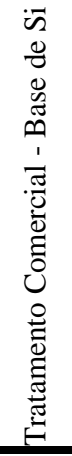 & 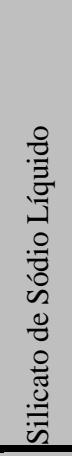 \\
\hline Potencial de Corrosão & 0,20 & 0,70 & 2,03 & 3,16 & 2,04 & 1,66 & 0,76 & 5,00 & 4,11 & 0,57 & 1,03 & 1,32 \\
\hline Velocidade de Corrosão & 0,04 & 0,52 & 1,15 & 1,72 & 1,18 & 1,18 & 0,51 & 2,50 & 2,50 & 0,40 & 0,73 & 2,19 \\
\hline Carga Passante & 0,15 & 0,39 & 1,04 & 1,54 & 1,23 & 2,54 & 0,43 & 5,00 & 4,28 & 0,32 & 0,91 & 0,71 \\
\hline$\sum$ Corrosão & 0,39 & 1,61 & 4,22 & 6,42 & 4,45 & 5,39 & 1,69 & 12,50 & 10,89 & 1,29 & 2,66 & 4,22 \\
\hline Profundidade de penetração de $\mathrm{Cl}$ & 0,11 & 0,31 & 0,76 & 1,23 & 0,91 & 1,34 & 0,43 & 10,72 & 5,36 & 0,26 & 0,94 & 0,67 \\
\hline $\begin{array}{r}\text { Coeficiente de difusão de cloretos } \\
\text { (estado não estacionário) }\end{array}$ & 0,07 & 0,18 & 0,45 & 0,53 & 0,46 & 0,77 & 0,18 & 2,14 & 1,77 & 0,14 & 0,40 & 0,36 \\
\hline $\begin{array}{r}\text { Coeficiente de difusão de cloretos } \\
\text { (estado estacionário) }\end{array}$ & 0,01 & 0,09 & 0,43 & 0,83 & 0,42 & 0,62 & 0,11 & 2,14 & 1,71 & 0,07 & 0,38 & 0,25 \\
\hline$\sum$ Pen & $\mathbf{0 , 2 0}$ & $\mathbf{0 , 5 9}$ & 1,64 & 2,59 & 1,80 & 2,72 & 0,71 & 15,00 & $\mathbf{8 , 8 3}$ & 0,47 & 1,72 & 1,28 \\
\hline Absorção de água por imersão & 0,07 & 0,29 & 0,95 & 2,06 & 0,51 & 0,64 & 0,16 & 2,67 & 1,76 & 0,13 & 0,23 & 0,24 \\
\hline Absorção de água por capilaridade & 0,04 & 0,26 & 0,95 & 4,13 & 1,16 & 4,25 & 0,26 & 9,00 & 9,00 & 0,22 & 0,41 & 0,39 \\
\hline Absorção pelo ensaio de pipeta & 0,06 & 0,23 & 0,91 & 1,89 & 0,81 & 2,13 & 0,39 & 3,00 & 2,75 & 0,10 & 0,20 & 0,19 \\
\hline ¿Penetração de Água & $\mathbf{0 , 1 7}$ & $\mathbf{0 , 7 8}$ & 2,81 & $\mathbf{8 , 0 8}$ & 2,47 & 7,01 & $\mathbf{0 , 8 0}$ & 14,67 & 13,51 & $\mathbf{0 , 4 4}$ & $\mathbf{0 , 8 5}$ & $\mathbf{0 , 8 3}$ \\
\hline$\sum$ TOTAL & 0,75 & 2,98 & 8,67 & 17,09 & 8,72 & 15,12 & 3,21 & 42,17 & 33,23 & 2,20 & 5,23 & 6,33 \\
\hline
\end{tabular}

Pode-se notar que, para todos os tipos de Proteção de Superfície se obteve melhor desempenho do que o elemento de Referência, o que mostra que é melhor o elemento de concreto ter um sistema de proteção, mesmo que seja de baixo desempenho, do que ficar com a estrutura desprotegida.

Para o sistema de proteção Hidrofugantes de Superfícies em todos os três níveis de análise o Hidrofugante $\mathrm{C}$ obteve maior nota de desempenho, o que o classifica como o melhor deste grupo. Foi esperado que o desempenho dos hidrofugantes à base de solvente fossem superiores aos de base d'água, pois como visto na 
OLIVEIRA, I. A; MEDEIROS, M. H. F., ESCOLHA DE PRODUTOS PARA PROTEÇÃO DE SUPERFÍCIE EM CONCRETOS FRENTE À AÇÃO DE ÍONS CLORETOS EM ZONAS MARÍTIMAS: UMA APLICAÇÃO DA ANÁLISE HIERÁRQUICA (AHP). $3^{\circ}$ Simpósio

Paranaense de Patologia das Construções (30 SPPC), artigo 3SPPC1004, pp. 35 - 46, 2018. DOI: 10.4322/2526-7248.004

literatura os solventes atingem uma profundidade maior de penetração nos elementos, o que garante melhor desempenho do produto de impregnação.

Para o grupo dos Formadores de Películas o produto com melhor desempenho em todos os níveis de avaliação foi o Verniz Poliuretânico PU-1 seguido pelo Verniz Poliuretânico PU-2 com desempenhos próximos. Como no grupo dos Hidrofugantes de Superfície, os protetores a base de solventes obtiveram também desempenhos superiores aos de base d'água.

Os Bloqueadores de Poros foram os que apresentaram menor desempenho. Este grupo foi o único que apresentou divergências entre os diferentes níveis de análises. Para os ensaios de Corrosão o produto de melhor desempenho foi o Silicato de Sódio Líquido, já para os ensaios de Penetração de Cloretos e Penetração de Água o produto que apresentou melhor desempenho foi o Tratamento Comercial a Base de Silicatos. Então, se houver a opção de utilização deste tipo de produto de proteção, é importante saber exatamente qual o tipo de ataque que o elemento estrutural tem a maior probabilidade de sofrer, porque isto será preponderante para o bom desempenho e durabilidade do produto.

\section{Conclusão}

Através da aplicação da Análise Hierárquica pode-se comparar com segurança dados que antes não eram passíveis de comparação. A organização em forma de hierarquia ajudou na organização das prioridades de cada critério e também na formulação do raciocínio para a atribuição das notas e posterirormente na interpretação das tabelas. Um ponto forte deste método para este trabalho foi o de reduzir dúvidas nos momentos das escolhas consideradas subjetivas.

Logo, para os ensaios de Penetração de Cloretos o melhor protetor de superfície foi o PU-1 bicomponente, em segundo lugar os protetores hidrofugantes e em terceiro os bloqueadores de poros. O segundo e o terceiro protetor tiveram desempenhos próximos, porém inferiores aos formadores de películas.

A contribuição deste trabalho é importante para sanar dúvidas sobre a escolha do melhor produto de proteção de superfícies ao ataque de íons cloretos. Assim, a Análise Hierárquica como ferramenta de decisão se demostrou eficiente para a escolha do melhor produto de proteção. Ainda assim, mesmo que a Análise Hierárquica apresente resultado favorável para certos grupos de protetores é necessário conhecer o tipo de ataque que estará incidindo no elemento estrutural a ser protegido.

Para este trabalho o protetor de superfície que apresentou melhor desempenho foi do grupo dos Formadores de Películas, o produto foi o Verniz Poliuretânico PU 1 Bicomponente.

\section{Referências}

[1] J. Hola and M. Ksiazek, "Research on usability of sulphur polymer composite for corrosion protection of reinforcing steel in concrete," vol. IX, no. 1, pp. 1316, 2009. 
OLIVEIRA, I. A; MEDEIROS, M. H. F., ESCOLHA DE PRODUTOS PARA PROTEÇÃO DE SUPERFÍCIE EM CONCRETOS FRENTE À AÇÃO DE ÍONS CLORETOS EM ZONAS MARÍTIMAS: UMA APLICAÇÃO DA ANÁLISE HIERÁRQUICA (AHP). $3^{\circ}$ Simpósio

Paranaense de Patologia das Construções (30 SPPC), artigo 3SPPC1004, pp. 35 - 46, 2018. DOI: 10.4322/2526-7248.004

[2] J. Newman and B. S. Choo, Advance concrete technology: constituent material, Elsevier. 2003.

[3] J. B. Aguiar, A. Camões, and P. M. Moreira, "Coatings for Concrete Protection against Aggressive Environments," vol. 6, no. 1, pp. 243-250, 2008.

[4] ACl Committee 201.2R-01, "Guide to durable concrete," ACI Committee 201. p. 53, 2008.

[5] M. H. F. Medeiros and P. Helene, "Surface treatment of reinforced concrete in marine environment: Influence on chloride diffusion coefficient and capillary water absorption," Construction and Building Materials, vol. 23, no. 3, pp. 1476-1484, 2009.

[6] L. Bertolini and R. Polder, Corrosion of Steel in Concrete. Weinheim, Alemanha: Wiley-VCH Verlag GmbH \& Co. KGaA, 2013.

[7] M. H. F. Medeiros and P. Helene, "Efficacy of surface hydrophobic agents in reducing water and chloride ion penetration in concrete," pp. 59-71, 2008.

[8] M. Khanzadeh, M. Shekarchi, and M. Hoseini, "Time-dependent performance of concrete surface coatings in tidal zone of marine environment," Construction and Building Materials, vol. 30, pp. 198-205, 2012.

[9] D. Standard, "Repair of concrete structures to EN 1504: a guide for renovation of concrete structures - repair materials and systems according to EN 1504 series." Elsevier Ltd, London, p. 214, 2004.

[10] Y. Dang, N. Xie, A. Kessel, E. Mcvey, A. Pace, and X. Shi, "Accelerated laboratory evaluation of surface treatments for protecting concrete bridge decks from salt scaling," Construction and Building Materials, vol. 55, pp. 128135, 2014.

[11] M. H. F. Medeiros, "Contribuição ao estudo da durabilidade de concretos com proteção superficial frente à ação de íons cloretos," USP, 2008.

[12] A. Almusallam, F. M. Khan, and M. Maslehuddin, "Performance of concrete coatings under varying exposure conditions," vol. 35, no. 1, pp. 487-494, 2002.

[13] L. Baltazar, J. Santana, B. Lopes, M. P. Rodrigues, and J. R. Correia, "Surface skin protection of concrete with silicate-based impregnations : Influence of the substrate roughness and moisture," Construction and Building Materials, vol. 70, pp. 191-200, 2014.

[14] J. T. Ramos, "Obtenção e caracterização de revestimentos protetores a base de silanos e sua combinação com tintas na proteção ao aço-carbono," Universidade Federal do Rio Grande do Sul, 2009.

[15] J. L. Thompson, M. R. Silsbee, P. M. Gill, and B. E. Scheetz, "Characterization of silicate sealers on concrete," Cement and Concrete Research, vol. 27, no. Vol. 27, pp. 1561-1567, 1997.

[16] M. H. F. De Medeiros, T. S. Gomes, and P. Helene, "Hidrofugantes de superfície: Estudo da capacidade de barrar o ingresso de água no concreto Surface hydrophobic agents : Study of the capacity of stopping water penetration in concrete," pp. 21-28, 2006.

[17] ASTM, "E 1765 - 02 Standard Practice for Applying Analytical Hierarchy Process ( AHP ) to Multiattribute Decision Analysis of Investments Related to Buildings and Building Systems 1," vol. 4. pp. 1-14, 2002. 